Adams, G., Fryberg, S.A., Garcia, D. M., \& Delgado-Torres, E. U. (2006). The psychology of engagement with indigenous identities: A cultural perspective. Cultural Diversity and Ethnic Minority Psychology, 12, 493-508. Publisher's Version: http://dx.doi.org/10.1037/1099-9809.12.3.493.

Open Access version: http://kuscholarworks.ku.edu/dspace/.

[This document contains the author's accepted manuscript. For the publisher's version, see the link in the header of this document.]

\title{
The Psychology of Engagement with Indigenous Identities: A Cultural Perspective
}

\author{
Glenn Adams* \\ University of Kansas and University of Toronto \\ Stephanie A. Fryberg \\ University of Arizona \\ Donna M.Garcia \\ Elizabeth U. Delgado-Torres \\ University of Kansas
}

Glenn Adams, Department of Psychology, University of Kansas and Department of Psychology, University of Toronto; Stephanie Fryberg, Department of Psychology, University of Arizona; Donna Garcia and Elizabeth U.Delgado-Torres, Department of Psychology, University of Kansas. Address correspondence concerning this article to Glenn Adams, Department of Psychology, University of Kansas,1415 Jayhawk Blvd., Lawrence, KS, 66045. Email: adamsg@ku.edu

\section{Paper citation:}

Adams, G., Fryberg, S.A., Garcia, D. M., \& Delgado-Torres, E. U. (2006). The psychology of engagement with Indigenous identities: A cultural perspective. Cultural Diversity and Ethnic Minority Psychology, 12, 493-508.

\section{Keywords:}

Liberation psychology, identity, social representation, self-esteem, well-being

\begin{abstract}
:
In a questionnaire study among 124 students at Haskell Indian Nations University, the authors investigated the hypothesis that engagement with Indigenous identity--assessed along three dimensions including degree (identification scale), content (panethnic or tribal nation), and context (reservation or nonreservation)--can serve as a psychological resource for well-being and liberation from oppression. Consistent with this hypothesis, degree of identification was positively correlated with community efficacy and perception of racism. Apparently inconsistent with this hypothesis, degree of identification among students who had resided on a reservation was negatively correlated with the Social Self-Esteem subscale of the Current Thoughts Scale. Rather than evidence against the identity-as-resource hypothesis, this pattern may reflect the cultural grounding of self-esteem and tools designed to measure it.
\end{abstract}


Adams, G., Fryberg, S.A., Garcia, D. M., \& Delgado-Torres, E. U. (2006). The psychology of engagement with indigenous identities: A cultural perspective. Cultural Diversity and Ethnic Minority Psychology, 12, 493-508. Publisher's Version: http://dx.doi.org/10.1037/1099-9809.12.3.493.

Open Access version: http://kuscholarworks.ku.edu/dspace/.

\title{
The Psychology of Engagement with Indigenous Identities: A Cultural Perspective
}

\author{
GLENN ADAMS* \\ University of Kansas and University of Toronto \\ STEPHANIE A. FRYBERG \\ University of Arizona \\ DONNA M.GARCIA \\ ELIZABETH U. DELGADO-TORRES \\ University of Kansas
}

\section{This is an Author Final Draft of the following paper: \\ Adams, G., Fryberg, S.A., Garcia, D. M., \& Delgado-Torres, E. U. (2006). The psychology of engagement with Indigenous identities: A cultural perspective. Cultural Diversity and Ethnic Minority Psychology, 12, 493-508.}

\section{Please refer to the published paper for citation purposes.}

A questionnaire study among 124 students at Haskell Indian Nations University investigated the hypothesis that engagement with Indigenous identity - assessed along 3 dimensions including degree (identification scale), content (pan-ethnic or tribal nation), and context (reservation or non-reservation) — can serve as a psychological resource for well-being and liberation from oppression. Consistent with this hypothesis, degree of identification was positively correlated with community efficacy and perception of racism. Apparently inconsistent with this hypothesis, degree of identification among students who had resided on a reservation was negatively correlated with the social self-esteem subscale of the Current Thoughts Scale (Heatherton \& Polivy, 1991). Rather than evidence against the identity-as-resource hypothesis, this pattern may reflect the cultural grounding of self-esteem and tools designed to measure it. Keywords: liberation psychology, identity, social representations, self-esteem, well-being

\footnotetext{
Glenn Adams, Department of Psychology, University of Kansas and Department of Psychology, University of Toronto; Stephanie Fryberg, Department of Psychology, University of Arizona; Donna Garcia and Elizabeth U. Delgado-Torres, Department of Psychology, University of Kansas.

The authors thank colleagues at Haskell Indian Nations University for the opportunity to conduct research, In particular, they thank Dustina Edmo Abrahamson, Venida Chenault, Beverly Dennis, Fredina Drye-Romero, Antonie Dvorakova, Ray Farve, Melissa Holder, John Howland, Claude Laird, Dawn Tato, and Michael Tosee for comments on research, assistance collecting data, or ongoing work on the project. Address correspondence concerning this article to Glenn Adams, Department of Psychology, University of Kansas, 1415 Jayhawk Blvd., Lawrence, KS, 66045.Email: adamsg@ku.edu
} 
Adams, G., Fryberg, S.A., Garcia, D. M., \& Delgado-Torres, E. U. (2006). The psychology of engagement with indigenous identities: A cultural perspective. Cultural Diversity and Ethnic Minority Psychology, 12, 493-508. Publisher's Version: http://dx.doi.org/10.1037/1099-9809.12.3.493. Open Access version: http://kuscholarworks.ku.edu/dspace/.

This research applies a cultural perspective to the phenomenon of ethnic identity among Indigenous Peoples in the USA. ${ }^{1}$ We first discuss dimensions of variation in the experience of Indigenous identities. Beyond the typical focus on degree of identification, a cultural perspective directs attention to two additional dimensions of variation: the content of identity representations and the context of identity experience. We then investigate the consequences of variation along these dimensions for well-being and collective action. A guiding concern is the extent to which Indigenous identity can serve as a resource to protect people from the harmful effects of societal oppression (Branscombe, Schmitt, \& Harvey, 1999; Oyserman, Harrison, \& Bybee, 2001).

\section{Variations in Engagement With Indigenous Identities}

\section{Degree of Engagement with Indigenous Identities}

To date, research has considered variation in ethnic identity almost exclusively in terms of stage or degree of identification (Cross, Parham, \& Helms, 1991): the extent to which people embrace an ethnic category and apply it to their experience. Framed as such, the idea of identity as a resource suggests that greater degrees of

\footnotetext{
${ }^{1}$ Guidelines of the American Psychological Association dictate the use of American Indian or Native American to refer to the communities in which the authors conducted the study. However, people who inhabit these communities vary in their preferences for different identity labels, and prescriptions concerning use of different labels are the subject of heated debate. For example, some writers have criticized labels like Indian, American Indian, and Native American as "counterfeit" identities imposed by European American colonizers as tools of racist subjugation (e.g., Yellow Bird, 2004). The present study represents an initial attempt to investigate the psychological consequences associated with different forms of identity representation. In the meantime, mindful of critiques from within the settings in which we conducted the research, we use Indigenous Peoples as the pan-ethnic representation for participants in the study.
}

identification will be associated with more positive outcomes. However, what constitutes greater identification is a subject of disagreement; competing conceptions and measures of identity abound in the literature. Although a detailed review is beyond the scope of the present paper (Ashmore, Deaux, \& McLauglin-Volpe, 2004; Phinney, 1996; Sellers, Smith, Shelton, Rowley, \& Chavous, 1998), a cultural perspective suggests that this abundance of competing measures may reflect variation in the construction of ethnic identity across particular communities.

\section{Content of Engagement with Indigenous Identities}

An important aspect of variation in the construction of ethnic identity is the content of identity. Rather than a single, self-evident category, there are multiple representations of Indigenous identity with which people might identify. In some cases, different identity representations constitute parallel categories (e.g., "racial" categories like Native American and White or tribal nation identities like Choctaw and Navajo). In other cases, representations vary within a nested-hierarchical model that Trimble (2000) describes in the following quote:

Within a tribe an American Indian may selfidentify as a member of a clan, outside the tribe among other American Indians as a member of a particular tribe, among non-Indians as an Indian, and outside the country as an American. (p. 199)

Rather than variation between parallel categories, this quote refers to variation along a hierarchy organized from local (clan) to global (nationality) categories.

As an initial investigation of content of Indigenous identity, the present study considers the distinction between tribal nation and panethnic representations. The former refers to relatively local representations, like Lakota or Navajo, organized around specific traditions of language and culture. The latter refers to more inclusive representations, like American Indian 
Adams, G., Fryberg, S.A., Garcia, D. M., \& Delgado-Torres, E. U. (2006). The psychology of engagement with indigenous identities: A cultural perspective. Cultural Diversity and Ethnic Minority Psychology, 12, 493-508. Publisher's Version: http://dx.doi.org/10.1037/1099-9809.12.3.493. Open Access version: http://kuscholarworks.ku.edu/dspace/.

or Native American, that are a product of the ongoing colonial encounter with (predominantly) European settlers. Although one might refer to both forms of identification as "ethnic," the present research investigates whether identification with one representation or another has different implications for well-being and collective action (Portes \& Rumbaut, 2001). To the extent that Indigenous communities have greater control over the meaning of relatively "local" tribal nation representations than relatively "global" pan-ethnic representationsthat is, greater opportunity for both authorship of "liberating" representations that reflect local experience and censorship of "othering" representations that reflect projections of mainstream imaginations - one can hypothesize that identification in terms of tribal nation representations will be associated with greater well-being and collective action than identification in terms of pan-ethnic representations.

\section{Context of Engagement with Indigenous Identities}

Also explicit in the quote by Trimble (2000) is another dimension of variation in experience of ethnic identity: context of engagement. When people inhabit settings populated mainly by nonIndigenous Peoples (where mainstream American constructions of reality are prominent), pan-ethnic representations like American Indian or Native American may provide the most relevant categories for experience of identity (McGuire, McGuire, Child, \& Fujoika, 1978). However, in settings populated mainly by Indigenous Peoples from different communities (e.g., intertribal associations), tribal nation representations may provide the most relevant categories for experience of identity.

There are many ways to understand context and its potential influence on experience of identity. In the present study, we focus on one dimension of contextual variation that is relevant in the case of Indigenous Peoples: reservation experience. Without reifying this dimension into a rigid dichotomy, people who have resided on reservations are likely to be more engaged with Indigenous worldviews than people who have not resided on reservations (Fryberg \& Markus, 2006). ${ }^{2}$ Accordingly, one can hypothesize that people who have resided in reservation settings should report greater engagement with Indigenous identities - and experience the hypothesized benefits for well-being and action - than people who have not resided in reservation settings.

\section{Implications of Engagement With Indigenous Identities for Important Outcomes}

The preceding section considers variation in Indigenous identity. The next section considers implications of this variation for self-esteem, community efficacy, and perception of racism..

\section{A Conventional Measure of Well-Being: Self- Esteem}

A comprehensive review of the self-esteem literature is beyond the scope of this paper (Gray-Little \& Hafdahl, 2000; Twenge \& Crocker, 2002). Instead, we follow precedent (Branscombe et al., 1999; Sellers et al., 1998) and use self-esteem as an indicator of well-being.

A cultural perspective suggests that the relationship between ethnic identity and selfesteem depends on the meaning of identity. To

\footnotetext{
${ }^{2}$ As one reviewer noted, some non-reservation communities do maintain a strong sense of tribal culture and identity. People in these non-reservation settings may resemble people from reservation settings in their patterns of engagement with Indigenous identity, including relative preference for tribal nation representations. Likewise, as another reviewer noted, reservation communities differ in many ways (e.g., casino wealth or lack thereof). We therefore emphasize that our use of reservation background does not imply rigid dichotomy. Rather, we use it as a rough dimension suitable for an initial investigation of the role of context on engagement with Indigenous identity. A more finely tuned analysis of contextual variation awaits future research.
} 
Adams, G., Fryberg, S.A., Garcia, D. M., \& Delgado-Torres, E. U. (2006). The psychology of engagement with indigenous identities: A cultural perspective. Cultural Diversity and Ethnic Minority Psychology, 12, 493-508. Publisher's Version: http://dx.doi.org/10.1037/1099-9809.12.3.493.

Open Access version: http://kuscholarworks.ku.edu/dspace/.

the extent that mainstream American society is filled with representations that portray Indigenous Peoples in a negative light, one might expect that people who identify strongly with this devalued group may suffer decreased self-esteem as a result (Allport, 1954). However, people who find identities under attack need not allow negative associations to taint personal selfesteem. Instead, they can buffer self-esteem by either redefining the self in ways that deemphasize its connection to the devalued category or by redefining the category in a more positive light (Gurin, Miller, \& Gurin, 1980; Tajfel \& Turner, 1986). Thus, the association between self-esteem and identification with a devalued group need not be negative and may even be positive (Branscombe et al., 1999; Sellers \& Shelton, 2003).

The redefinition of devalued categories is not merely an individual activity, but also occurs at the level of cultural representations. Some communities may create liberating worldviews that provide alternative, less derogatory accounts of ethnic position than the stigmatizing accounts that prevail in mainstream society (Carmichael \& Hamilton, 1967; Fanon, 1963; Martín-Baró, 1994). These liberating worldviews may buffer self-esteem by providing conceptual resources needed to challenge mainstream constructions of social reality. With respect to Indigenous Peoples, examples of liberating worldviews include attempts to challenge mainstream interpretations of historical events (e.g., framing Columbus Day as commemoration of genocide rather than celebration of "discovery"; Yellow Bird, 2004; Nagel, 1996) or to redefine individual manifestations of distress in terms of intergenerational trauma (Duran \& Duran, 1995).

One can hypothesize that people who engage constructions of identity that are grounded in Indigenous worldviews may show a more positive (or less negative) association between ethnic identity and self-esteem than do people who engage constructions of Indigenous ethnicity that are grounded in the colonizers' constructions. The corresponding hypothesis is that people who report tribal nation identities or who have resided in reservation settings will show more positive correlations between selfesteem and degree of ethnic identification.

Similarly, the relationship between identity and self-esteem may depend on the meaning of self-esteem. Although most research on this relationship has tended to assume that selfesteem has similar meaning across groups, a cultural perspective suggests that self-esteem may mean different things in different settings (Heine, Lehman, Markus \& Kitayama, 1999). For example, research has noted a tendency for Indigenous people to score lower on measures of self-esteem than do people from other ethnic groups in North America (Twenge \& Crocker, 2002). The meaning and extent of this pattern is the subject of considerable debate (Gray-Little \& Hafdahl, 2000), and empirical research has tended to yield contradictory conclusions (Trimble, 1987). However, a cultural perspective emphasizes that the tendency for people from Indigenous communities to score lower on measures of self-esteem does not necessarily mean that they suffer low levels of self-respect, self-regard, or other forms of positive selffunctioning (Heine et al., 1999). Instead, conventional measures of self-esteem developed among mainstream populations may not adequately capture positive self-experience among Indigenous people. Moreover, to the extent that Indigenous worldviews are associated with lower scores on mainstream measures of self-esteem, a cultural perspective suggests the hypothesis that increasing engagement with Indigenous worldviews - as indicated by reservation experience, preference for tribal nation designation, and scores on conventional measures of ethnic identification - should be associated with lower scores on mainstream measures of self-esteem.

\section{An Alternative Measure of Well-Being: Community Efficacy}

In light of the cultural critique described in the preceding paragraph, the present research 
Adams, G., Fryberg, S.A., Garcia, D. M., \& Delgado-Torres, E. U. (2006). The psychology of engagement with indigenous identities: A cultural perspective. Cultural Diversity and Ethnic Minority Psychology, 12, 493-508. Publisher's Version: http://dx.doi.org/10.1037/1099-9809.12.3.493. Open Access version: http://kuscholarworks.ku.edu/dspace/.

supplements a focus on self-esteem with a measure of well-being that may be more appropriate in Indigenous settings: community efficacy (Bandura, 2000). One benefit of this concept is to extend research focus from the level of individual self to the level of collective self. Another benefit is to extend research focus beyond the esteem dimension of self-experience to the efficacy dimension. More generally, the concept of community efficacy represents an important outcome to the extent that it fosters and affords community action in the fight against oppression.

\section{Perception of racism}

Another outcome that has become the focus of research on the implications of ethnic identity has been perception of racism. Among European Americans, high degrees of engagement with White identity are negatively associated with perceptions of racism in society (Nelson, Branscombe, Adams, \& Schmitt, 2005). Among people from stigmatized, ethnic minority groups, high levels of ethnic identity are positively associated with perceptions of racism in society (Branscombe et al., 1999; Operario \& Fiske, 2001; Sellers \& Shelton, 2003).

However, the more typical focus of research on perception of racism has not been its relationship to ethnic identity, but rather its implications for self-esteem (Major, Quinton, \& McCoy, 2002; Schmitt \& Branscombe, 2002). On one hand, perception of racism entails acknowledgment that society devalues one's social identity, which could lead to increased stress and depressed self-esteem (Branscombe, et al., 1999). On the other hand, perception of racism may promote increased self-esteem to the extent that it helps people accurately anticipate and control situations in which they are, in fact, targets of racism (Sechrist, Swim, \& Stangor, 2004).

Regardless of its implications for self-esteem, perception of racism can be beneficial to the extent that it sensitizes people to actual oppression. If people do not identify instances of oppression, they are unlikely to mobilize resources to defend themselves against it. Thus, like community efficacy, one can interpret perception of racism as an indicator of processes related to liberation from oppression (Fanon, 1963; Martín-Baró, 1994; Sellers et al., 1998).

\section{Overview of Research}

This paper explores variation in engagement with Indigenous identity and its implications for wellbeing and collective action. Specifically, we consider three dimensions of variation in engagement with Indigenous identity: degree (i.e., a conventional identification scale), content (i.e., tendency to use tribal nation versus panethnic representations), and context (i.e., reservation experience). We investigate the implications of this variation for three outcomes: a three-dimensional measure of self-esteem, collective efficacy, and perception of racism.

The guiding hypothesis is that greater engagement with Indigenous identity will be associated with more positive outcomes.

Regarding degree of engagement, this translates into the more specific hypotheses that higher scores on the identification scale will be associated with greater (a) self-esteem, (b) collective efficacy, and (c) perceptions of racism. Regarding content of engagement, this translates into the more specific hypotheses that participants who use tribal nation representations will report greater (d) self-esteem, (e) collective efficacy, and (f) perceptions of racism than do participants who use pan-ethnic representations. Finally, regarding context of engagement, this translates into the more specific hypotheses that participants who report reservation experience will report greater $(\mathrm{g})$ self-esteem, $(\mathrm{h})$ collective efficacy, and (i) perceptions of racism than do participants who do not report reservation experience.

Hypotheses (a), (d), and (g) assume that conceptions and measurement of self-esteem are similar in Indigenous and mainstream American 
Adams, G., Fryberg, S.A., Garcia, D. M., \& Delgado-Torres, E. U. (2006). The psychology of engagement with indigenous identities: A cultural perspective. Cultural Diversity and Ethnic Minority Psychology, 12, 493-508. Publisher's Version: http://dx.doi.org/10.1037/1099-9809.12.3.493.

Open Access version: http://kuscholarworks.ku.edu/dspace/.

settings. In contrast, a cultural perspective suggests the engagement with Indigenous worldviews may be associated with lower scores on mainstream measures of self-esteem. This translates into the specific hypotheses that (a') higher scores on the identification scale, (d') the tendency to use tribal nation representations, and $\left(g^{\prime}\right)$ the tendency to report reservation experience will be associated with lower self-esteem scores.

Finally, in addition to the preceding hypotheses, a more exploratory research question is whether the implications of variation in degree or content of engagement vary with the context of identification (i.e., reservation experience). This pattern corresponds to the statistical interaction of reservation experience with either degree or content of engagement. A significant interaction implies that the consequences of engagement (e.g., as represented by hypotheses (a) to (f) in the earlier paragraph) differ for people who do and do not report reservation experience.

\section{Method}

\section{Participants}

Participants were 124 students at Haskell Indian Nations University. The university provides tuition-free education in a culturally based curriculum for approximately 1000 students who must prove membership in a federally recognized, Indigenous community. Although located in Lawrence, KS, students come from Indigenous communities across the USA (including Alaska), with the greatest concentration from Plains and Southwest regions. We recruited participants from a variety of classes (American Indian Studies, Introduction to Psychology, and Introduction to Sociology) to help insure a representative sample. Demographic characteristics closely match those of samples in subsequent research, suggesting that this sample is representative of students at Haskell. Half of participants reported that they had lived on an
Indian reservation (34 females, 28 males) and half reported that they had never lived on an Indian reservation (28 females, 34 males). Participants ranged in age from 18 to 35 years, with a median age of 21 years. They received no compensation for participation.

\section{Materials}

The first page of the survey included open-ended items about ethnic affiliation, gender, age, year in school, and hometown. The rest of the survey included measures of self-esteem, community efficacy, ethnic identification, and perceptions of racism (in that order). ${ }^{3}$

\section{SELF-ESTEEM. The Current Thoughts Scale} (CTS; Heatherton \& Polivy, 1991) served as a measure of state self-esteem. The CTS consists of 20 items for which participants use a 5-point scale $(1=$ not at all, $5=$ extremely $)$ to indicate how they feel "right now." The purpose of the CTS is not to assess an individual's characteristic level of self-esteem, but instead to assess current experience of self-regard. An important feature of the CTS is that it consists of three subscales measuring different aspects of self-regard. These include a 6-item appearance subscale ("I feel satisfied with the way my body looks right now"; $\alpha=.77$ ), a 7-item performance subscale ("I feel confident about my abilities" [reverse scored]; $\alpha$ $=.76$ ), and a 7-item social subscale ("I am worried about what other people think of me"; $\alpha$ $=.81$ ). Items on the social subscale are coded such that high scores indicate less concern with other people's attention, which is associated in mainstream American settings with high selfesteem.

\footnotetext{
${ }^{3}$ Nearly all students completed the open-ended item about ethnic affiliation with Native American or American Indian. Without information to the contrary or the explicit opportunity to provide alternative information, participants appeared to assume that the investigators desired officially sanctioned categories used by U.S. government institutions.
} 
Adams, G., Fryberg, S.A., Garcia, D. M., \& Delgado-Torres, E. U. (2006). The psychology of engagement with indigenous identities: A cultural perspective. Cultural Diversity and Ethnic Minority Psychology, 12, 493-508. Publisher's Version: http://dx.doi.org/10.1037/1099-9809.12.3.493.

Open Access version: http://kuscholarworks.ku.edu/dspace/.

COMMUNITY EFFICACY. Measures of selfesteem typically focus on the individual self. To assess self-regard at the level of collective self, we adapted a measure from our previous research (Fryberg, Markus, Oyserman, \& Stone, 2006) to create an indicator of community efficacy.

Participants used a 5-point scale ( $1=$ not at all, 5 $=$ extremely) to indicate agreement with four items $(\alpha=.77)$ : (1) "People in my community have a number of good qualities," (2) "I care how others think about my community," (3) "I feel like I can make a difference in my community," and (4) "People in my community can take action to make things better." Besides its focus on the collective self, the emphasis on action rendered this measure useful as an indicator of processes related to liberation from oppression.

\section{DEGREE OF IDENTIFICATION: ETHNIC} IDENTIFICATION SCALE. Following research on the role of identity as a resource (e.g., Oyserman, Bybee, \& Terry, 2003), we used six items from the Racial Identification Scale (RIS; Oyserman et al., 2001) to assess degree of engagement with Indigenous identity. In particular, we combined items from the connectedness (e.g., "It is important to me to think of myself as an American Indian.") and embedded achievement (e.g., "If I am successful, it will help the American Indian community.") subscales of the RIS to form an index of engagement with Indigenous identity $(\alpha=.85)$. Participants used a 5-point scale ( 1 = strongly disagree, 5 = strongly agree) to indicate their agreement with each statement.

\section{CONTENT OF IDENTITY: IDENTITY}

REPRESENTATION. An important goal of the present research was to extend attention beyond degree of identification to consider content of identification. Participants indicated which of a set of six identity descriptions-American, Native American, Indian, American Indian, Tribal Nation, and Other - best described how they experienced their identity at the present moment. We coded whether participants selected a tribal nation representation $(1=$ yes, $0=$ no $)$ to create a dichotomous indicator of identity content.

PERCEPTIONS OF RACISM. The final measure was a 16-item instrument $(\alpha=.88)$ that assessed perceptions of racism. We adapted this measure from previous research (Adams, Tormala, \& O'Brien, in press; Branscombe et al., 1999) to reflect issues of relevance for Indigenous Peoples. The items consisted of hypothetical situations (e.g., "A real estate agent takes an American Indian couple to look only at homes in low-income neighborhoods.") and actual events (e.g., "The use of American Indians as mascots by colleges and professional teams"). Participants used a 7-point scale $(1=$ no role, $7=$ a large role $)$ to indicate the extent to which racism played a role in each event. The mean of each participant's responses constituted their perception of racism score.

\section{Procedure}

After each instructor introduced her, Fryberg (who identifies as Snohomish from the Tulalip reservation in Washington State) explained the goals of the research, assured students of confidentiality, educated them about their rights as participants, and invited them to participate. After completion, participants placed the consent form and survey in separate boxes to further assure anonymity. Researchers debriefed them regarding the background of the study and thanked them for participating. Participation took approximately 30-40 minutes.

\section{Results}

The first purpose of the study was to investigate variation in the engagement with Indigenous identities. Accordingly, we assessed the extent to which both degree and content of engagement varied as a function of reservation background, gender, and year in school. Because we measured 
Adams, G., Fryberg, S.A., Garcia, D. M., \& Delgado-Torres, E. U. (2006). The psychology of engagement with indigenous identities: A cultural perspective. Cultural Diversity and Ethnic Minority Psychology, 12, 493-508. Publisher's Version: http://dx.doi.org/10.1037/1099-9809.12.3.493.

Open Access version: http://kuscholarworks.ku.edu/dspace/.

degree of engagement with a continuous variable (ethnic identification scale) the appropriate technique was analysis of variance (ANOVA). Because we measured content with a categorical variable (identity representation), the appropriate technique was loglinear analysis, for which partial associations between combinations of predictors and the categorical outcome variable are analogous to main effects and interactions in ANOVA (Marascuilo \& Busk, 1987).

The second purpose of the study was to consider implications of variation in identity for well-being (indicated by self-esteem) and processes related to liberation from oppression (community efficacy and perception of racism). The general hypothesis was that engagement with Indigenous identity would be positively related to these outcomes. To assess this hypothesis, we conducted analyses of all outcomes as a function of gender, year in school, and each dimension of variation in engagement. We used regression techniques for analyses involving the continuous indicator of degree (ethnic identification scale) and ANOVA techniques for analyses involving the categorical indicators of content (identity representation) and context (reservation background).

Initial analyses indicated that distributions for all Likert-type scales (i.e., ethnic identity scale, three self-esteem subscales, community efficacy, and perception of racism) met the assumption of normality. In the analyses that follow, we report results that were significant at $p=.05$.

\section{Variation in Engagement with Indigenous Identities}

To assess variation in degree of engagement, we conducted a 2 (Reservation Background: none or some) x 2 (Gender: men or women) x 2 (Year in School: first or second) ANOVA of identification scores. Results revealed a main effect of reservation background, $F(1,116)=13.05, p=$ $.001, \eta^{2}=.10$. Participants who reported reservation experience $(M=4.50, S D=0.50)$ had higher identification scores than did participants who did not $(M=4.07, S D=0.74)$.

To assess variation in content of engagement, we conducted a loglinear analysis of the identity representation (pan-ethnic or tribal nation), using the three categorical predictors from the preceding analysis. Results revealed a partial association of Reservation Background $\mathrm{x}$ Year in School x Identity Representation, $\chi^{2}(1, N=124)$ $=6.25, p<.013$ (i.e., a Reservation Background $\mathrm{x}$ Year in School interaction in ANOVA terms). Follow-up analyses revealed an association of reservation background with identity content that was limited to first-year students. Although 41\% of first year students who reported reservation experience indicated a tribal nation representation, only $7 \%$ of students who did not report reservation experience did so, $\chi^{2}(1, N=62)$ $=8.87, p=.003$. The percentage of second-year students who indicated a tribal nation representation did not vary as a function of reservation background (i.e., 29\% for both groups).

In general, results suggest that engagement with Indigenous identity varied in predictable ways as a function of reservation background. Participants who reported reservation background had higher identification scores and - at least among first-year students - were more likely to report tribal nation identity than were participants who did not report reservation background.

\section{Implications of Variation in Degree of Engagement: Ethnic Identification Scale}

To assess implications of variation in degree of engagement, we conducted regression analyses with ethnic identification scores, gender, year in school and the higher-order interaction terms composed of these variables as predictors of each outcome. In support of hypotheses (b) and (c), results revealed relationships of ethnic identification scores with community efficacy, $\beta$ $=.505, p<.001$, and perceptions of racism $\beta=$ $.378, p=.015$. In contrast, there was no evidence 
Adams, G., Fryberg, S.A., Garcia, D. M., \& Delgado-Torres, E. U. (2006). The psychology of engagement with indigenous identities: A cultural perspective. Cultural Diversity and Ethnic Minority Psychology, 12, 493-508. Publisher's Version: http://dx.doi.org/10.1037/1099-9809.12.3.493. Open Access version: http://kuscholarworks.ku.edu/dspace/.

for hypothesis (a) regarding positive relationships between ethnic identification and measures of self-esteem. No other relationships approached conventional levels of statistical significance.

\section{Implications of Variation in Content of Engagement: Identity Representations}

To assess implications of variation in content of engagement, we performed a 2 (Identity

Representation: tribal or pan-ethnic) x 2 (Gender: women or men) x 2 (Year in School: first or second) Multivariate Analysis of Variance (MANOVA) on the five dependent outcomes plus the ethnic identification scale. The results revealed a significant Identity Representation $\mathrm{x}$ Gender interaction, Wilks' $\lambda=0.892, F(6,111)=$ $2.25, p=.044, \eta^{2}=.11$.

To interpret this multivariate result, we conducted 2 × 2 ANOVAs separately for each outcome. These univariate analyses revealed only a Gender x Identity Representation interaction for appearance self-esteem, $F(1,116)=5.66, p=$ $.019, \eta^{2}=.05$. To interpret this interaction, we assessed the simple effects of identity representation within each gender. These analyses revealed an association of identity representation with appearance self-esteem - that is, support for hypothesis (d) - that was limited to women, $F(1$, $120)=6.39, p=.013, \eta^{2}=.052$. Appearance selfesteem was greater for women who indicated a tribal nation representation $(M=3.81, S D=0.66)$ than for women who indicated a pan-ethnic representation $(M=3.32, S D=0.65)$. Values for men were $M=3.43, S D=0.80$ and $M=3.60, S D$ $=0.70, F(1,116)=1.09, p=.300, \eta^{2}=.009$.

In contrast to this evidence in support of hypothesis (d), results provided no support for hypotheses (e) and (f) regarding associations of identity representation with community efficacy and perception of racism. Likewise, results provided no evidence of any association between use of tribal nation representation and scores on the ethnic identification scale.
Implications of Variation in Context of Engagement: Reservation Background

To assess implications of variation in context of engagement, we conducted a 2 × 2 × 2 MANOVA on the five outcome measures with reservation background, gender, and year in school as factors. These analyses revealed a main effect of reservation background, Wilks' $\lambda=0.849, F(5$, $112)=3.99, p=.002, \eta^{2}=.18$. To interpret this multivariate main effect, we conducted $2 \times 2 \times 2$ ANOVAs separately for each outcome. Results of univariate tests for main effects of reservation background appear in Table 1. In support of hypothesis (i), students with reservation experience reported greater perception of racism than students with no reservation experience. Likewise, results revealed a trend consistent with hypothesis $(\mathrm{h})$, such that students with reservation experience reported greater community efficacy than students with no reservation experience. In contrast, but in support of hypothesis ( $\left.\mathrm{g}^{\prime}\right)$, students with reservation experience indicated lower levels of self-esteem on all three subscales (i.e., performance, social, and appearance) than students with no reservation experience.

\section{Multiple Regression Analyses with Ethnic Identification and Reservation Background}

Separate analyses of reservation background and degree of identification indicate significant relationships of these variables with the outcomes of community efficacy and perception of racism. However, because there was also a strong relationship between these two variables, it is relevant to ask whether relationships between one of the variables and the outcome measures may be mediated by its relationship to the other variable. Following Baron and Kenny (1986), we conducted mediation analyses in which we considered ethnic identification and reservation background as simultaneous predictors of community efficacy and perception of racism. (Initial analyses indicated that the Ethnic 
Adams, G., Fryberg, S.A., Garcia, D. M., \& Delgado-Torres, E. U. (2006). The psychology of engagement with indigenous identities: A cultural perspective. Cultural Diversity and Ethnic Minority Psychology, 12, 493-508. Publisher's Version: http://dx.doi.org/10.1037/1099-9809.12.3.493.

Open Access version: http://kuscholarworks.ku.edu/dspace/.

ENGAGEMENT WITH INDIGENOUS IDENTITIES

Table 1 Mean differences in outcomes as a function of reservation background

\begin{tabular}{lccccc}
\hline & No reservation & Reservation & $F(1,116)$ & $p$ & $\eta^{2}$ \\
\hline Performance Self-esteem & $3.95(0.56)$ & $3.67(0.65)$ & 7.62 & .007 & .062 \\
Social Self-esteem & $3.87(0.59)$ & $3.53(0.85)$ & 9.33 & .003 & .074 \\
Appearance Self-esteem & $3.65(0.63)$ & $3.34(0.75)$ & 6.18 & .014 & .051 \\
Community Efficacy & $3.27(0.91)$ & $3.61(0.78)$ & 3.10 & .081 & .026 \\
Perception of Racism & $5.06(1.19)$ & $5.48(0.85)$ & 5.03 & .027 & .042 \\
\hline
\end{tabular}

Note. $N \mathrm{~s}=62$

Identification x Reservation Background interaction term was not a significant predictor of any outcome, so we do not discuss it further.) Results indicated that the relationships of ethnic identification with community efficacy $\beta=0.431$, $p<.001$ and perception of racism, $\beta=0.348, p<$ .001 remained significant. In contrast, previously significant relationships with reservation background were no longer significant for community efficacy $(\beta=0.06, p=.50)$ and perception of racism $(\beta=0.09, p=.32)$. Sobel's (1982) tests confirmed that the indirect relationships of reservation background mediated through identification score were significantly different from zero for community efficacy, $z=$ $3.02, p=.003$ and perception of racism, $z=2.73$, $p=.006$. These patterns suggest that the associations of reservation background with these two outcomes were mediated by identification scores.

We also conducted multiple regression analyses with ethnic identification and reservation background as simultaneous predictors of the three self-esteem subscales. Because analyses had revealed no significant relationships between degree of identification and self-esteem, mediation analyses were inappropriate. Instead, the purpose of these analyses was to consider the exploratory research question noted in the Introduction: namely, whether relationships between identification and self-esteem changed as a function of reservation background.

To address this issue, we regressed each selfesteem subscale on identification score, reservation background, and the interaction of these two variables. Results indicated a significant, Ethnic Identification x Reservation Background interaction only for scores on the social self-esteem subscale, $\beta=-1.42, t(120)=$ $2.10, p=.038$. To interpret this interaction, we analyzed the relationship between identification and social self-esteem separately for participants with and without reservation experience. These analyses revealed no relationship between identification and social self-esteem scores for people with no reservation experience, $\beta=0.035$, $t(60)<1$. However, there was a significant, negative relationship between identification and social self-esteem scores among people with reservation experience, $\beta=-0.257, t(60)=-2.06$, $p<.043$. This pattern constitutes support for hypothesis (a') although limited to social selfesteem scores among participants with reservation experience.

\section{Discussion}

Results provide initial evidence for the general hypothesis that engagement with Indigenous identity is positively associated with indicators of well-being and collective action. One source of evidence for this hypothesis involves quantitative differences in degree of identification. Students who scored higher on the scale measure of identification also tended to report greater community efficacy and perception of racism. Previous research has documented a positive relationship between ethnic identification and perception of racism among African American 
Adams, G., Fryberg, S.A., Garcia, D. M., \& Delgado-Torres, E. U. (2006). The psychology of engagement with indigenous identities: A cultural perspective. Cultural Diversity and Ethnic Minority Psychology, 12, 493-508. Publisher's Version: http://dx.doi.org/10.1037/1099-9809.12.3.493. Open Access version: http://kuscholarworks.ku.edu/dspace/.

(Branscombe et al., 1999; Sellers \& Shelton, 2003) and Latino participants (Operario \& Fiske, 2001). The present research documents a similar pattern among Indigenous participants.

How is one to interpret the association between ethnic identification and racism perception? One interpretation is that racism perception fosters identification. That is, perception of racism may promote a sense of rejection by American society, which may lead people to identify with (and find greater acceptance among) other Indigenous people who have been similarly rejected (Branscombe et al., 1999). From this perspective, increased identification can serve as a resource to the extent that it helps buffer the consequences of mainstream rejection.

Alternatively, increased identification may promote perception of racism. People who identify strongly with Indigenous communities are likely to experience increased engagement with Indigenous constructions of reality, including those that emphasize the role of racist oppression as an explanation for past injustice and continuing disadvantage. From this perspective, increased identification can serve as a resource by providing people with liberating worldviews, sensitizing them to the threat of racist oppression, and fostering a sense of collective efficacy with which to combat this threat (Gurin et al., 1980; Martín-Baró, 1994, p. $30)$.

Another source of evidence for the role of identity as a resource comes from differences in content of identification. The general hypothesis was that use of representations that resonated closely with Indigenous constructions of identity would be associated with more positive outcomes than use of representations rooted in mainstream constructions of identity. The present study investigated this hypothesis by considering the distinction between tribal nation and pan-ethnic representations. To the extent that identification with tribal nation representations signals greater engagement with Indigenous constructions of identity than does identification with pan-ethnic representations, people who typically identify themselves in terms of the former should report better outcomes than people who typically identify themselves in terms of the latter.

Results for appearance self-esteem provide limited support for this hypothesis. Women who indicated a tribal nation representation reported higher appearance self-esteem than did women who indicated a pan-ethnic representation. One interpretation of this pattern is that the tendency to identify in terms of tribal nation representations reflects greater engagement with Indigenous worldviews. Engagement with Indigenous worldviews may buffer appearance self-esteem by protecting Indigenous women from potentially damaging, mainstream constructions of beauty and providing them with realistic standards that more closely fit their bodies.

Beyond evidence that tribal nation representations are associated with greater appearance self-esteem among Indigenous women, results provided little evidence of hypothesized relationships involving identity content for other outcomes. However, one should not interpret observed results as an indication that the content of identity representations is inconsequential. Instead, an important step for future research is to move beyond the distinction between tribal nation and pan-ethnic

representations. Although this distinction implies that tribal nation representations indicate greater engagement with Indigenous worldviews than pan-ethnic representations, the reality is more complicated. Representations vary in their resonance with Indigenous worldviews within both pan-ethnic (e.g. First Nations versus American Indian) and tribal nation (Lakota versus Sioux) categories. Future work can benefit from a qualitative approach that attends more closely to differences in meaning of various identity representations.

Although the idea of identity as a resource implies that variations in identification affect outcomes of interest, the correlational nature of the present research does not rule out causal 
Adams, G., Fryberg, S.A., Garcia, D. M., \& Delgado-Torres, E. U. (2006). The psychology of engagement with indigenous identities: A cultural perspective. Cultural Diversity and Ethnic Minority Psychology, 12, 493-508. Publisher's Version: http://dx.doi.org/10.1037/1099-9809.12.3.493.

Open Access version: http://kuscholarworks.ku.edu/dspace/.

relationships in the reverse direction (e.g., that well-being affects identification) or joint causation by a "third variable". Conclusive evidence for the idea of identity as a resource awaits research that examines the effect of changes in Indigenous identification - whether experimentally manipulated or naturally occurring —on subsequent outcomes.

\section{Contributions of a Cultural Perspective}

CONTENT OF IDENTIFICATION. Besides a focus on identity as a resource, another contribution of the present research is to apply a cultural perspective to the study of ethnic identity. One feature of a cultural perspective is a focus on the content of identity representations. Identification is more than engagement (or not) with a naturally existing, ethnic category. Instead, people have available to them a variety of identity representations that vary in meaning and implications for important outcomes. People are not passive recipients of these representations, but instead contribute to the reproduction of these representations through everyday acts of appropriation (Gone, Miller, \& Rappaport., 1999). An adequate account of ethnic identification must transcend the tendency to treat received identity categories as natural or inevitable and begin to highlight the collective construction processes that create, reproduce, and maintain these categories.

CONTEXT OF IDENTIFICATION. Another feature of a cultural perspective is a focus on the context of identification. One expression of this focus is the variable of reservation background. Students who had resided on a reservation tended to report higher degrees of ethnic identification than students who had not resided on a reservation, and this accounted for further differences in measures of community efficacy and perception of racism.

Likewise, first-year students with reservation experience were more likely to indicate tribal nation representations than were first-year students without reservation experience. In reservation settings, differences between tribal nations - in terms of language, customary practices, and material culture - may be very salient dimensions along which to construct one's identity. However, experience in non-reservation settings may be more strongly influenced by mainstream American constructions in which the most salient dimensions of difference are not tribal nation representations, but pan-ethnic categories made real by the census and other official documents.

Among second-year students, there were no differences in use of tribal nation representations as a function of reservation background. As a space inhabited almost exclusively by people who claim some form of Indigenous identity, the constructions of reality that inform everyday experience at Haskell may be those-like tribal nation representations - that resonate with Indigenous communities. Likewise, when one finds oneself in situations (like Haskell) where one can assume that everyone claims some form of Indigenous identity, there is little utility in identifying oneself according to pan-ethnic representations. Instead, consistent with the quote about the situated experience of Indigenous identity (Trimble, 2000), the more salient or relevant form of identification may be tribal nation representations (McGuire et al., 1978).

Implicit in this discussion is a dynamic account in which patterns of ethnic selfidentification change over the course of a student's career. However, this account remains speculative given the cross-sectional nature of the present research. More conclusive evidence for this account awaits longitudinal research that tracks individual students' patterns of identification over time.

CULTURAL GROUNDING OF PSYCHOLOGICAL SCIENCE. A third feature of a cultural

perspective is attention to the cultural grounding of psychological science. The science of psychology often proceeds as if its measures and constructs reflect deeply embedded, natural 
Adams, G., Fryberg, S.A., Garcia, D. M., \& Delgado-Torres, E. U. (2006). The psychology of engagement with indigenous identities: A cultural perspective. Cultural Diversity and Ethnic Minority Psychology, 12, 493-508. Publisher's Version: http://dx.doi.org/10.1037/1099-9809.12.3.493.

Open Access version: http://kuscholarworks.ku.edu/dspace/.

features of human psyche that transcend cultural and historical context. In contrast, a cultural perspective considers the extent to which these measures and constructs reflect particular social realities.

This perspective is important for making sense of the apparently anomalous pattern in which people who had resided on a reservation reported lower self-esteem on all three subscales than did people who had not resided on a reservation. Taken at face value, this pattern would appear to contradict the idea of identity as a resource because greater engagement with Indigenous worldviews, as indicated by reservation background, was associated with lower self-esteem. Regression analyses for social self-esteem afford a similar conclusion. Rather than a resource to preserve self-esteem, high degrees of identification were related to lower scores on the social self-esteem subscale among students who had resided on a reservation. What is one to make of these patterns? Does increased engagement with Indigenous identity result in low self-esteem?

A closer look at the items of the social selfesteem subscale suggests a potential answer. Many of these items (e.g., "I am worried about what other people think of me") express a concern about the relationship of self to social environment. Within mainstream American constructions of reality (which disproportionately inform theory and research in psychology), endorsement of these items may indeed reflect an "unhealthy" concern about the social environment that limits elaboration and enhancement of the individual self. In a setting where elaboration and enhancement of the individual self is a local imperative, failure to follow one's inner voice may be associated with poor outcomes. However, these poor outcomes may be less the product of pan-human nature and more the result of the particular constructions of self that prevail in mainstream-American spaces (Heine et al., 1999).

Concern about the relationship of self to social environment may represent a less problematic way of being in many Indigenous communities. Rather than elaboration and enhancement of the individual self, people in many Indigenous communities may engage worlds in which explicit and implicit norms advocate attention and tuning of self to the social environment. More generally, constructions of self-esteem in many Indigenous communities may deviate from the constructions of self-esteem that prevail in mainstream psychological science (Dvorakova, 2003).

So, rather than evidence against the idea of Indigenous identity as a resource, results for selfesteem may instead reflect the cultural grounding of psychological science (Gergen, Gulerce, Lock, $\&$ Misra, 1996). Adequate evaluation of hypotheses about well-being in Indigenous communities may require conceptions and measures of self-esteem that resonate more strongly with these communities. Equally important, attempts to measure psychological experience using conceptions developed in mainstream American worlds may yield distorting conclusions (and perpetuate relationships of domination) if one fails to consider their status as cultural and historical artifacts (Duran \& Duran, 1995; Greenfield, 1997; Smith, 1999).

\section{Concluding Comments: Implications for Practice}

Given the preliminary status of the present research, one should regard the preceding paragraph more as a caution about possibility than a conclusive explanation for observed results. We take the liberty to elaborate this possibility here, despite its speculative nature, to emphasize the benefits of a cultural perspective. Although this discussion has focused on conception and measurement of self-esteem, one can advocate a similar approach to the study of ethnic identification. Rather than assume a transcultural process of ethnic identification, we advocate increased attention to the ways in which the conception and measurement of identity is 
Adams, G., Fryberg, S.A., Garcia, D. M., \& Delgado-Torres, E. U. (2006). The psychology of engagement with indigenous identities: A cultural perspective. Cultural Diversity and Ethnic Minority Psychology, 12, 493-508. Publisher's Version: http://dx.doi.org/10.1037/1099-9809.12.3.493.

Open Access version: http://kuscholarworks.ku.edu/dspace/.

grounded in particular constructions of reality.

With that caution in mind, it is important to stress a similar caution about the contextual grounding of the present research. Participants in this study were students at Haskell Indian Nations University, a unique institution where pan-ethnic, Indigenous identity - rather than more specific, tribal nations or more general, mainstream American society - provides the common ground for everyday interaction. Accordingly, as with any study addressing issues of cultural diversity, there should be no expectation that particular patterns observed in this study constitute essential features of "Indigenous" psychology that one could apply, regardless of context, to all people identified with that category.

However, it bears repeating that the point of a cultural perspective - as in the present study - is not to catalog the essential properties of artificially reified groups. Instead, the more important point is to reveal how psychological processes like ethnic identification are rooted in particular cultural patterns, social representations, and other constructions of reality (Adams \& Markus, 2004). Accordingly, we hesitate to give recommendations for counseling or mental health practitioners based on our specific results - for example, to reify the analytic dimension of reservation background and advocate different measurement procedures for students who reside in reservation and non-reservation settings. Instead, a cultural perspective recommends two broad orientations to practice. The first is attention to the context of assessment and the extent to which standard measures and constructs are cultural artifacts (Greenfield, 1997). The second is attention to the content of identity, including the search for liberating representations of Indigenous identity and practices that afford people from Indigenous communities greater control over the meaning of these representations.

\section{References}

Adams, G. \& Markus, H. R. (2004). Toward a conception of culture suitable for a Social Psychology of Culture. In M. Schaller \& C. S. Crandall (Eds.), The psychological foundations of culture (pp. 335-360). Mahwah, NJ: Lawrence Erlbaum Associates.

Adams, G., Tormala, T. T., \& O'Brien, L. (in press). The effect of self-affirmation on perceptions of racism. Journal of Experimental Social Psychology, 42.

Allport, G. W. (1954). The nature of prejudice. Cambridge, MA: Addison-Wesley.

Ashmore, R. Deaux, K., \& McLaughlin-Volpe, T. (2004). An organizing framework for collective identity: Articulation and significance of multidimensionality. Psychological Bulletin, 130, 80-114.

Bandura, A. (2000). Exercise of human agency through collective efficacy. Current Directions in Psychological Science, 9, 7578.

Baron, R.M. \& Kenny, D.A. (1986). The Moderator-Mediator variable distinction in Social Psychological research: Conceptual, strategic, and statistical considerations. Journal of Personality and Social Psychology, 51, 1173-1182.

Branscombe, N., Schmitt, M., \& Harvey, R. (1999). Perceiving pervasive discrimination among African Americans: Implications for group identification and well-being. Journal of Personality and Social Psychology, 77, 135-149.

Carmichael, S. \& Hamilton, C. V. (1967). Black power: The politics of liberation in America. New York: Vintage Books.

Cross, W., \& Parham, T., \& Helms, J. (1991). The stages of Black identity development: Nigrescence models. In Jones, R. (eds.), Black Psychology (pp. 319-338). Berkeley, CA: Cobb and Henry.

Duran, E. \& Duran, B. (1995). Native American postcolonial psychology. Albany, NY: SUNY Press. 
Adams, G., Fryberg, S.A., Garcia, D. M., \& Delgado-Torres, E. U. (2006). The psychology of engagement with indigenous identities: A cultural perspective. Cultural Diversity and Ethnic Minority Psychology, 12, 493-508. Publisher's Version: http://dx.doi.org/10.1037/1099-9809.12.3.493.

Open Access version: http://kuscholarworks.ku.edu/dspace/.

Dvorakova, A. (2003). The notion of low selfesteem among Indigenous Peoples of the USA and the strength of Indigenous self-regard. Indigenous Nations Studies Journal, 4, 1-23. Fanon, F. (1963). Wretched of the Earth. (C. Farrington, Trans.). New York: Grove Press.

Fryberg, S. A. \& Markus, H. R. (2006). Cultural models of education in American Indian, Asian American, and European American contexts. Unpublished manuscript, University of Arizona.

Fryberg, S. A., Markus, H. R., Oyserman, D., \& Stone, J. M. (2006). Honor or harm? The impact of using American Indian mascots on American Indian selves. Unpublished manuscript, University of Arizona.

Gergen, K. J., Gulerce, A., Lock, A., \& Misra, G. (1996). Psychological science in cultural context. American Psychologist, 51, 496-503.

Gone, J. P., Miller, P. J., \& Rappaport, J. (1999). Conceptual narrative as normatively oriented: The suitability of past personal narrative for the study of cultural identity. Culture and Psychology, 5, 371-398.

Gray-Little, B., \& Hafdahl A. R. (2000). Factors influencing racial comparisons of selfesteem: A quantitative review. Psychological-Bulletin, 126, 26-54.

Greenfield, P. M. (1997). You can't take it with you: Why ability assessments don't cross cultures. American Psychologist, 52, 11151124.

Gurin, P., Millar, A.H. \& Gurin, G. (1980) Stratum identification and consciousness. Social Psychology Quarterly 43: 30-47

Heatherton, T. F. \& Polivy, J. (1991). Development and validation of a scale for measuring state self-esteem. Journal of Personality and Social Psychology, 60, 895910.

Heine, S. H., Lehman, D. R., Markus, H. R., \& Kitayama, S.(1999). Is there a universal need for positive self-regard? Psychological Review, 106, 766-794.

Major, B., Quinton, W. J., \& McCoy, S. K. (2002). Antecedents and consequences of attributions to discrimination: Theoretical and empirical advances. In M. P. Zanna (Ed.), Advances in experimental social psychology: Vol. 34. (pp.251-330). San Diego, CA: Academic Press.

Marascuilo, L. A., \& Busk, P. L. (1987). Loglinear models: A way to study main effects and interactions for multidimensional contingency tables with categorical data. Journal of Counseling Psychology, 34, 443455.

Martín-Baró, I. (1994) Writings for a liberation psychology. (A. Aron and S. Corne, Eds.). Cambridge, MA: Harvard University Press. McGuire, W. J., McGuire, C. V., Child, P., \& Fujioka, T. (1978). Salience of ethnicity in the spontaneous self-concept as a function of one's ethnic distinctiveness in the social environment. Journal of Personality and Social Psychology, 36, 511-520.

Nagel, J. (1996). American Indian ethnic renewal: Red power and the resurgence of identity and culture. New York: Oxford University Press.

Nelson, J.C., Branscombe, N.R., Adams, G., \& Schmitt, M. T. (2005). Historical knowledge and endorsement of race-based conspiracy beliefs. Unpublished manuscript. Lawrence, KS.

Operario, D., \& Fiske, S. T. (2001). Ethnic identity moderates perceptions of prejudice: Judgments of personal versus group discrimination and subtle versus blatant bias. Personality and Social Psychology Bulletin, 27, 550-561.

Oyserman, D., Bybee, D. \& Terry, K. (2003). Gendered racial identity and involvement with school. Self and Identity, 2, 307-324.

Oyserman, D., Harrison, K., \& Bybee, D. (2001). Can racial identity be promotive of academic efficacy? International Journal of Behavioral Development, 25, 379-385.

Phinney, J. S. (1996). When we talk about American ethnic groups, what do we mean? American Psychologist, 51, 918-927.

Portes, A. \& Rumbaut, R. G. (2001). Legacies: 
Adams, G., Fryberg, S.A., Garcia, D. M., \& Delgado-Torres, E. U. (2006). The psychology of engagement with indigenous identities: A cultural perspective. Cultural Diversity and Ethnic Minority Psychology, 12, 493-508. Publisher's Version: http://dx.doi.org/10.1037/1099-9809.12.3.493.

Open Access version: http://kuscholarworks.ku.edu/dspace/.

The story of the immigrant second generation. Berkeley, CA: University of California Press.

Schmitt, M. T., \& Branscombe, N. R. (2002). The meaning and consequences of perceived discrimination in disadvantaged and privileged social groups. European Review of Social Psychology, 12, 167-199.

Sechrist, G. B., Swim, J. K., \& Stangor, C. (2004). When do the stigmatized make attributions to discrimination occurring to the self and others? The roles of self-presentation and need for control. Journal of Personality and Social Psychology, 87, 111-122.

Sellers, R. M., \& Shelton, J. N. (2003). The role of racial identity in perceived racial discrimination. Journal of Personality and Social Psychology, 84, 1079-1092.

Sellers, R.M., Smith, M.A., Shelton, J.M.. Rowley, S.A.J., \& Chavous, T.M. (1998). Multidimensional model of racial identity: A reconceptualization of African American racial identity. Personality and Social Psychology Review, 2, 18-39.

Smith, L. T. (1999). Decolonizing methodologies: Research and indigenous peoples. London: Zed Books.

Sobel, M. E. (1982). Asymptotic confidence intervals for indirect effects in structural equations models. In S. Leinhart (Ed.), Sociological methodology 1982 (pp. 290312). San Francisco: Jossey-Bass.

Tajfel, H. and Turner, J. C. (1986). The social identity theory of inter-group behavior. In S. Worchel and L. W. Austin (eds.), Psychology of Intergroup Relations. Chigago: NelsonHall.

Trimble, J. E. (1987). Self-perception and perceived alienation among American Indians. Journal of Community Psychology, 15, 316-333.

Trimble, J. E. (2000). Social psychological perspectives on changing self-identification among American Indians and Alaska Natives. In R. H. Dana (Ed.), Handbook of crosscultural and multicultural personality assessment (pp. 197-222). Hillsdale, NJ: Erlbaum.

Twenge, J. M., \& Crocker, J. (2002). Race and self-esteem: Meta-analyses comparing Whites, Blacks, Hispanics, Asians, and American Indians and comment on GrayLittle and Hafdahl (2000). Psychological Bulletin, 128, 371-408.

Yellow Bird, M. (2004). Cowboys and Indians: Toys of genocide, icons of colonialism. Wicazo Sa Review, 18, 33-48. 